\title{
Antiestrogen use reduces risk of cervical neoplasia in breast cancer patients: a population-based study
}

\author{
Chia-Jung Hsieh ${ }^{1, *}$, Mun-Kun Hong ${ }^{2,3, *}$, Pau-Chung Chen ${ }^{4,5,6}$, Jen-Hung Wang ${ }^{7}$ and \\ Tang-Yuan $\mathrm{Chu}^{2,3}$ \\ ${ }^{1}$ Department of Public Health, Tzu Chi University, Hualien, Taiwan, ROC \\ 2 Department of Obstetrics and Gynecology, Buddhist Tzu Chi General Hospital, Hualien, Taiwan, ROC \\ ${ }^{3}$ Institute of Medical Sciences, Tzu Chi University, Hualien, Taiwan, ROC \\ ${ }^{4}$ Department of Public Health, National Taiwan University College of Public Health, Taipei, Taiwan, ROC \\ ${ }^{5}$ Institute of Occupational Medicine and Industrial Hygiene, National Taiwan University College of Public Health, Taipei, \\ Taiwan, ROC \\ ${ }^{6}$ Department of Environmental and Occupational Medicine, National Taiwan University Hospital and National Taiwan University \\ College of Medicine, Taipei, Taiwan, ROC \\ 7 Department of Medical Research, Buddhist Tzu Chi General Hospital, Hualien, Taiwan, ROC \\ * These authors have contributed equally to this work
}

Correspondence to: Tang-Yuan Chu, email: hidrchu@gmail.com

Keywords: cervical neoplasia, antiestrogen, aromatase inhibitor, tamoxifen, cervical cancer

Received: August 15, $2016 \quad$ Accepted: October 17, $2016 \quad$ Published: October 27, 2016

Copyright: Hsieh et al. This is an open-access article distributed under the terms of the Creative Commons Attribution License (CC-BY), which permits unrestricted use, distribution, and reproduction in any medium, provided the original author and source are credited.

\section{ABSTRACT}

Estrogen has been proven to be a necessity for cervical carcinogenesis by transgenic mice studies. To determine whether long-term antiestrogens use could reduce the incidence of cervical neoplasia, a population-based cohort of 42,940 breast cancer patients with and without antiestrogen therapy were identified from the Taiwan National Health Insurance Database. All patients were followed for the most severe form of cervical neoplasia or until death. Their risks of cervical neoplasia were compared with Cox regression analysis and adjusted for age, Pap smear density and chemotherapy. Aromatase inhibitor (AI)-included antiestrogen users consistently exhibited a lower risk of low-grade cervical dysplasia [adjusted hazard ratio (HR) $=0.42,95 \% \mathrm{CI} 0.29$ to $0.64, P<0.0001]$ in the five-year follow-up analysis and in subgroup of regular Pap screenings ( $\mathrm{HR}=0.32,95 \% \mathrm{CI}, 0.20$ to $0.50, P<0.0001$ ). A lower 10-year incidence of high-grade cervical dysplasia was also noted in the regular-screening group $(\mathrm{HR}=0.49 ; 95 \% \mathrm{CI}, 0.27$ to $0.90 ; P=0.0212)$, especially in the $\geq 50$ years old group $(\mathrm{HR}=0.34 ; 95 \% \mathrm{CI}, 0.14$ to $0.80 ; P=0.014)$. The protection effect of Tamoxifen-only use for low-grade cervical dysplasia was only found in the young-age, regular-screening group $(\mathrm{HR}=0.67 ; 95 \% \mathrm{CI}, 0.48$ to $0.93 ; P=0.0167)$. In short, long-term use of AI-included antiestrogen conferred a lower risk of cervical neoplasia.

\section{INTRODUCTION}

As the second most common malignancy in women worldwide, cervical cancer is the leading cause of cancer death in developing countries that lack organized Pap smear screening [1-3]. Epidemiologic studies have revealed that the long-term hormone exposure that occurs with high parity and oral contraceptive use is an independent risk factor for invasive cervical cancer (ICC) [4-5]. In unscreened populations of different countries, the incidence of ICC in women increases with age and plateaus in peri-menopause [6], suggesting a dependence on sex hormones. In the K14-HPV-E6/E7 transgenic mouse model of cervical cancer, an absolute requirement for estrogen and the estrogen receptor (ER) alpha has been proved in the full course of carcinogenesis $[7,8]$. Cervical neoplasias of differing severities did not appear unless the mice were treated with a physiological level of $17 \beta$-estradiol and had a functional Esrl gene [9]. Importantly, the administration of a selective estrogen 
Table 1: Demographics and clinical characteristics of the breast cancer cohort with 5 year follow-up

\begin{tabular}{|c|c|c|c|c|c|c|c|c|c|}
\hline \multirow[t]{2}{*}{ Characteristic } & \multicolumn{2}{|c|}{$\begin{array}{l}\text { All patients with } \\
\text { breast cancer } \\
(N=42940)\end{array}$} & \multicolumn{2}{|c|}{$\begin{array}{l}\text { Nonuser } \\
(N=15197, \\
\mathbf{3 5 . 7 \%})\end{array}$} & \multicolumn{2}{|c|}{$\begin{array}{l}\text { AI-included } \\
\text { user } \\
(N=7551, \\
17.7 \%)\end{array}$} & \multicolumn{2}{|c|}{$\begin{array}{l}\text { Tamoxifen only } \\
\text { user } \\
(N=19875 \\
46.6 \%)\end{array}$} & \multirow[t]{2}{*}{$P$-value } \\
\hline & $N$ & $\%$ & $N$ & $\%$ & $N$ & $\%$ & $N$ & $\%$ & \\
\hline SERM use & 25879 & 60.3 & - & - & 5687 & 75.3 & 19875 & 100.0 & - \\
\hline Tamoxifen & 25819 & 60.1 & - & - & 5664 & 75.0 & 19875 & 100.0 & \\
\hline Raloxifen & 157 & 0.4 & - & - & 62 & 0.8 & 0 & 0.0 & \\
\hline Toremifen & 250 & 0.6 & - & - & 96 & 1.3 & 0 & 0.0 & \\
\hline Clomifene & 73 & 0.2 & - & - & 4 & 0.1 & 0 & 0.0 & \\
\hline AI-included use $\mathrm{a}^{\mathrm{a}}$ & 7551 & 17.6 & - & - & 7551 & 100.0 & 0 & 0.0 & - \\
\hline Age at breast cancer diagnosis (years) & & & & & & & & & $\begin{array}{l}< \\
0.0001\end{array}$ \\
\hline $18-39$ & 5549 & 12.9 & 2116 & 13.9 & 314 & 4.2 & 3045 & 15.3 & \\
\hline $40-49$ & 13929 & 32.4 & 4260 & 28.0 & 1750 & 23.2 & 7820 & 39.4 & \\
\hline $50-59$ & 12490 & 29.1 & 5088 & 33.5 & 2787 & 36.9 & 4562 & 23.0 & \\
\hline$\geq 60$ & 10972 & 25.6 & 3733 & 24.6 & 2700 & 35.8 & 4448 & 22.4 & \\
\hline Year of breast cancer diagnosis & & & & & & & & & $\begin{array}{l}< \\
0.0001\end{array}$ \\
\hline 2002 & 2497 & 5.8 & 870 & 5.7 & 425 & 5.6 & 1162 & 5.9 & \\
\hline 2003 & 2555 & 6.0 & 946 & 6.2 & 461 & 6.1 & 1107 & 5.6 & \\
\hline 2004 & 2991 & 7.0 & 1068 & 7.0 & 600 & 8.0 & 1293 & 6.5 & \\
\hline 2005 & 3662 & 8.5 & 1299 & 8.6 & 724 & 9.6 & 1605 & 8.1 & \\
\hline 2006 & 3734 & 8.7 & 1283 & 8.4 & 781 & 10.3 & 1635 & 8.2 & \\
\hline 2007 & 4176 & 9.7 & 1420 & 9.3 & 888 & 11.8 & 1839 & 9.3 & \\
\hline 2008 & 4718 & 11.0 & 1616 & 10.6 & 928 & 12.3 & 2140 & 10.8 & \\
\hline 2009 & 5126 & 11.9 & 1824 & 12.0 & 932 & 12.3 & 2340 & 11.8 & \\
\hline 2010 & 5601 & 13.0 & 2012 & 13.2 & 877 & 11.6 & 2691 & 13.5 & \\
\hline 2011 & 5747 & 13.4 & 2030 & 13.4 & 765 & 10.1 & 2935 & 14.8 & \\
\hline 2012 & 2133 & 5.0 & 829 & 5.5 & 170 & 2.3 & 1128 & 5.7 & \\
\hline Chemotherapy for breast Cancer & 26927 & 62.7 & 10718 & 70.5 & 5332 & 70.6 & 10742 & 54.1 & $\begin{array}{l}< \\
0.0001\end{array}$ \\
\hline $\begin{array}{l}\text { Breast cancer diagnosis to follow up } \\
\text { start (day), median (IQR) }\end{array}$ & \multicolumn{2}{|c|}{141 (21 to197) } & \multicolumn{2}{|c|}{143 (18 to 196$)$} & \multicolumn{2}{|c|}{$160(35$ to 213$)$} & \multicolumn{2}{|c|}{$130(20$ to 190$)$} & $\begin{array}{ll}< \\
0.0001 \\
\end{array}$ \\
\hline $0-90$ & 16153 & 37.6 & 5034 & 33.1 & 2324 & 30.8 & 8616 & 43.4 & \\
\hline $91-180$ & 13084 & 30.5 & 5360 & 35.3 & 2188 & 29.0 & 5467 & 27.5 & \\
\hline $181-270$ & 10749 & 25.0 & 3209 & 21.1 & 2495 & 33.0 & 4988 & 25.1 & \\
\hline $271-360$ & 2954 & 6.9 & 1594 & 10.5 & 544 & 7.2 & 804 & 4.1 & \\
\hline Follow up period (year), median (IQR) & \multicolumn{2}{|c|}{$\begin{array}{l}3.76 \\
(1.83 \text { to } 5.00) \\
\end{array}$} & \multicolumn{2}{|c|}{$\begin{array}{l}3.52 \\
(1.65 \text { to } 5.00) \\
\end{array}$} & \multicolumn{2}{|c|}{$\begin{array}{l}4.11 \\
(2.29 \text { to } 5.00)\end{array}$} & \multicolumn{2}{|c|}{\begin{tabular}{|l|}
3.75 \\
$(1.82$ to 5.00$)$ \\
\end{tabular}} & $\begin{array}{ll}< \\
0.0001 \\
\end{array}$ \\
\hline Mortality & 3040 & 7.1 & 1627 & 10.7 & 806 & 10.7 & 583 & 2.9 & \begin{tabular}{|l|l|}
$<$ \\
0.0001 \\
\end{tabular} \\
\hline Antiestrogen adherence $^{\mathrm{b}}$ & & & & & & & & & - \\
\hline Nonuser & 15197 & 35.4 & 15197 & 100.0 & - & - & - & - & \\
\hline$<0.5$ & 2038 & 4.8 & - & - & 1405 & 18.6 & 5145 & 25.9 & \\
\hline $0.5-0.7$ & 4625 & 10.8 & - & - & 1276 & 16.9 & 3227 & 16.2 & \\
\hline $0.7-0.9$ & 4555 & 10.6 & - & - & 1493 & 19.8 & 3459 & 17.4 & \\
\hline$\geq 0.9$ & 5012 & 11.7 & - & - & 3377 & 44.7 & 8044 & 40.5 & \\
\hline Ever Pap smear & 29213 & 68.0 & 8895 & 58.5 & 5271 & 69.8 & 14807 & 74.5 & $\begin{array}{l}< \\
0.0001 \\
\end{array}$ \\
\hline Pap smear every two years ${ }^{\mathrm{c}}$ & 13389 & 31.2 & 3577 & 23.5 & 2174 & 28.8 & 7548 & 38.0 & $\begin{array}{l}< \\
0.0001\end{array}$ \\
\hline $\begin{array}{l}\text { Pap smear density (times/year), } \\
\text { median (IQR) }\end{array}$ & \multicolumn{2}{|c|}{$\begin{array}{l}0.40 \\
(0.00 \text { to } 0.78)\end{array}$} & \multicolumn{2}{|c|}{$\begin{array}{l}0.22 \\
(0 \text { to } 0.62)\end{array}$} & \multicolumn{2}{|c|}{$\begin{array}{l}0.40 \\
(0 \text { to } 0.76)\end{array}$} & \multicolumn{2}{|c|}{$\begin{array}{l}0.55 \\
(0 \text { to } 0.87)\end{array}$} & $\begin{array}{l}< \\
0.0001 \\
\end{array}$ \\
\hline $\begin{array}{l}\text { Antiestrogen accumulated } \\
\text { (cumulative dofined daily } \\
\text { median (IQR) }\end{array}$ & & & & & & & & & - \\
\hline
\end{tabular}




\begin{tabular}{|c|l|l|l|l|l|}
\hline Antiestrogen & - & - & $\begin{array}{l}949 \\
\text { (532 to 1490) }\end{array}$ & - & \\
\hline SERM & & & $\begin{array}{l}252 \\
\text { (7 to 681) }\end{array}$ & - \\
\hline Tamoxifen & - & - & $\begin{array}{l}245 \\
\text { (1 to 672) }\end{array}$ & $\begin{array}{l}742 \\
(382 \text { to } 1311)\end{array}$ \\
\hline AI $^{\text {a }}$ & - & - & 468 (196 to 868) & - & \\
\hline $\begin{array}{l}\text { AI cDDD/Antiestrogen cDDD (\%), } \\
\text { median (IQR) }\end{array}$ & - & - & 67 (31 to 99) & - & - \\
\hline
\end{tabular}

SERM: selective estrogen receptor modulator, AI: aromatase inhibitor; IQR: interquartile ranges, cDDD: cumulative defined daily dose

${ }^{a} A I$ : Exemestane or Letrozole or Anastrozole or Aminoglutethimide

${ }^{\mathrm{b}}$ Antiestrogen adherence $=$ cumulative defined daily dose /period of follow-up (day)

'Pap smear every two years: patients who had Pap smear at least once in every two years during follow-up

dPap smear density = number of Pap smear/ follow-up year

receptor modulator (SERM) led to the regression of the cervical neoplasias [10]. These findings suggest a pivotal role of estrogen and $\mathrm{ER} \alpha$ in cervical carcinogenesis. However, evidence from human cervical carcinogenesis is lacking [11-13].

Aromatase inhibitor (AI) and tamoxifen are the two major antiestrogens that have been prescribed for more than two decades as adjuvant therapies [14, 15], and recently as chemoprevention agents for breast cancer [16]. We conducted a nation-wide, population-based study to determine whether antiestrogen use is associated with a lower risk of cervical neoplasia in breast cancer patients.

\section{RESULTS}

We identified 87,333 eligible breast cancer patients who were registered for the first time in the RCIPD (Figure 1). After the exclusion criteria were applied, 42,940 patients were included in this study; 27,743 (64.6\%) were antiestrogen users, and 15,197 (35.4\%) were nonusers. Among the antiestrogen users, 25,819 (93.1\%) had used tamoxifen, 7,551 (27.5\%) had used aromatase inhibitor (AI-included users), 478 (1.7\%) had used other SERMs, and 5,967 (21.5\%) had used multiple antiestrogens during the study period (Figure 1). Among the AI-included users,

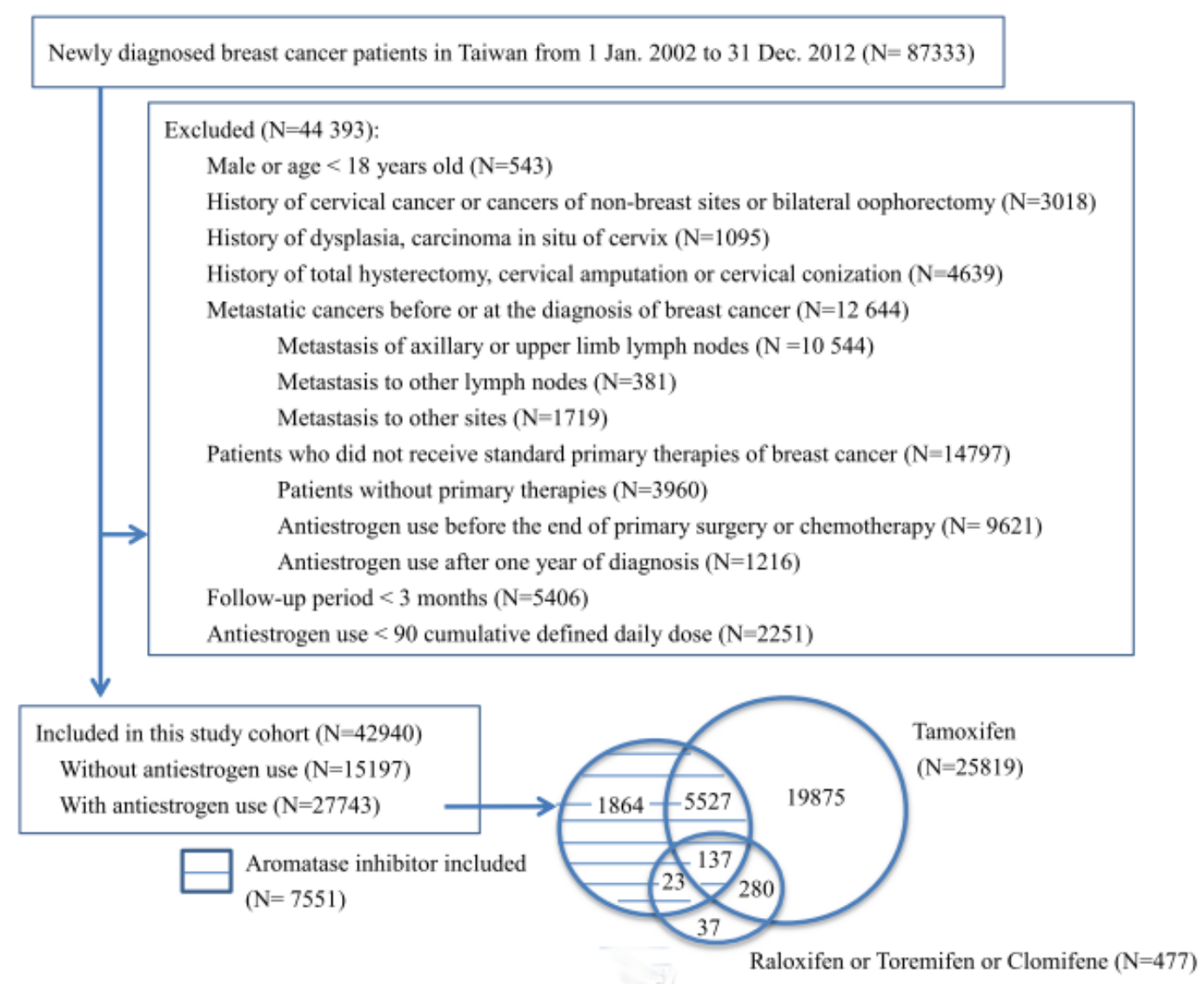

Figure 1: Selection of study population and status of antiestrogen use. 
Table 2: Association between antiestrogens use and incidence of cervical neoplasia in the breast cancer cohort

\begin{tabular}{|c|c|c|c|c|c|c|c|c|c|c|c|c|}
\hline & \multicolumn{6}{|c|}{5 year follow-up } & \multicolumn{6}{|c|}{10 year follow-up } \\
\hline & \multicolumn{3}{|c|}{ Low-grade dysplasia } & \multicolumn{3}{|c|}{ High-grade dysplasia } & \multicolumn{3}{|c|}{ High-grade dysplasia } & \multicolumn{3}{|c|}{ ICC } \\
\hline & Nonuser & $\begin{array}{c}\text { AI- } \\
\text { included }\end{array}$ & $\begin{array}{c}\text { Tamoxifen } \\
\text { only }\end{array}$ & Nonuser & $\begin{array}{c}\text { AI- } \\
\text { included }\end{array}$ & \begin{tabular}{|c|} 
Tamoxifen \\
only
\end{tabular} & Nonuser & $\begin{array}{c}\text { AI- } \\
\text { included }\end{array}$ & $\begin{array}{c}\text { Tamoxifen } \\
\text { only }\end{array}$ & Nonuser & \begin{tabular}{|c|} 
AI- \\
included
\end{tabular} & $\begin{array}{c}\text { Tamoxifen } \\
\text { only }\end{array}$ \\
\hline $\begin{array}{l}\text { No. of } \\
\text { patients }\end{array}$ & 15136 & 7516 & 19761 & 15076 & 7510 & 19660 & 14893 & 8084 & 19018 & 14843 & 8064 & 18935 \\
\hline $\begin{array}{l}\text { Patients } \\
\text { with event }\end{array}$ & 113 & 33 & 200 & 53 & 27 & 99 & 63 & 30 & 103 & 13 & 10 & 20 \\
\hline $\begin{array}{l}\text { Person- } \\
\text { years }\end{array}$ & 49154 & 26953 & 66633 & 49095 & 26942 & 66415 & 60919 & 38091 & 79764 & 60780 & 38025 & 79610 \\
\hline $\begin{array}{l}\text { Incidence } \\
\text { per } \\
10^{5} \text { person- } \\
\text { years }\end{array}$ & 230 & 122 & 300 & 108 & 100 & 149 & 103 & 79 & 129 & 21 & 26 & 25 \\
\hline $95 \% \mathrm{CI}$ & 191-276 & $86.8-172$ & $261-344$ & $82-141$ & $68-146$ & $122-181$ & $80-132$ & $55-112$ & $106-156$ & $12-36$ & $14-48$ & $16-38$ \\
\hline
\end{tabular}

HR: hazard ratio, ICC: invasive cervical cancer

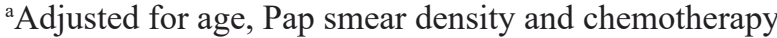

Table 3: Subgroup analysis of Cox's regression model for the association between antiestrogens use and cervical neoplasia

\begin{tabular}{|c|c|c|c|c|c|c|c|c|c|c|c|c|c|}
\hline \multirow{3}{*}{ Modela } & \multirow{3}{*}{$\begin{array}{l}\text { No. of } \\
\text { Patients }\end{array}$} & \multicolumn{8}{|c|}{5 year follow-up } & \multirow{2}{*}{\multicolumn{4}{|c|}{ 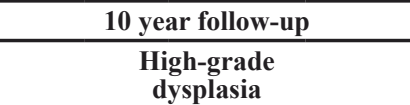 }} \\
\hline & & \multicolumn{4}{|c|}{$\begin{array}{l}\text { Low-grade } \\
\text { dysplasia }\end{array}$} & \multicolumn{4}{|c|}{$\begin{array}{l}\text { High-grade } \\
\text { dysplasia }\end{array}$} & & & & \\
\hline & & Event & HR & $95 \% \mathrm{CI}$ & $\begin{array}{c}P- \\
\text { value }\end{array}$ & Event & HR & $95 \%$ CI & $P$-value & Event & HR & $95 \% \mathrm{CI}$ & $P$-value \\
\hline All study population & 42623 & 346 & & & & 179 & & & & 196 & & & \\
\hline \multicolumn{14}{|l|}{ Main model } \\
\hline Nonuser & 15197 & 113 & 1.0 & & & 53 & 1.0 & & & 63 & 1.0 & & \\
\hline AI-included & 7551 & 33 & 0.42 & $0.29-0.64$ & $<0.0001$ & 27 & 0.73 & $0.45-1.16$ & 0.1780 & 30 & 0.60 & $0.39-0.93$ & 0.0231 \\
\hline Tamoxifen only & 19875 & 200 & 0.87 & $0.69-1.11$ & 0.2661 & 99 & 0.94 & $0.67-1.33$ & 0.7246 & 103 & 0.87 & $0.63-1.2$ & 0.3943 \\
\hline \multicolumn{14}{|l|}{ Age, years } \\
\hline \multicolumn{14}{|l|}{$18-49$} \\
\hline Nonuser & 6376 & 62 & 1.0 & & & 22 & 1.0 & & & 25 & 1.0 & & \\
\hline AI-included & 2064 & 13 & 0.40 & $0.22-0.74$ & 0.0031 & 13 & 1.19 & $0.59-2.38$ & 0.6315 & 14 & 0.93 & $0.48-1.81$ & 0.8298 \\
\hline Tamoxifen only & 10865 & 119 & 0.75 & $0.55-1.03$ & 0.0717 & 64 & 1.22 & $0.74-1.99$ & 0.4374 & 67 & 1.15 & $0.72-1.83$ & 0.5682 \\
\hline \multicolumn{14}{|l|}{$\geq 50$} \\
\hline Nonuser & 8821 & 51 & 1.0 & & & 31 & 1.0 & & & 38 & 1.0 & & \\
\hline AI-included & 5487 & 20 & 0.45 & $0.27-0.76$ & 0.0028 & 14 & 0.51 & $0.27-0.96$ & 0.0359 & 16 & 0.44 & $0.24-0.79$ & 0.0058 \\
\hline Tamoxifen only & 9010 & 81 & 1.04 & $0.73-1.49$ & 0.8319 & 35 & 0.74 & $0.45-1.21$ & 0.2305 & 36 & 0.67 & $0.42-1.07$ & 0.0922 \\
\hline $\begin{array}{l}\text { Pap smear every two } \\
\text { year }\end{array}$ & 13299 & 296 & & & & 128 & & & & 135 & & & \\
\hline \multicolumn{14}{|l|}{ Main model } \\
\hline Nonuser & 3541 & 95 & 1.0 & & & 34 & 1.0 & & & 36 & 1.0 & & \\
\hline AI-included & 2157 & 24 & 0.32 & $0.20-0.50$ & $<0.0001$ & 12 & 0.43 & $0.22-0.83$ & 0.0122 & 15 & 0.49 & $0.27-0.90$ & 0.0212 \\
\hline Tamoxifen only & 7455 & 177 & 0.78 & $0.61-1.01$ & 0.0565 & 82 & 1.01 & $0.67-1.52$ & 0.9556 & 84 & 1.01 & $0.68-1.50$ & 0.9690 \\
\hline \multicolumn{14}{|l|}{ Age, years } \\
\hline \multicolumn{14}{|l|}{$18-49$} \\
\hline Nonuser & 1694 & 53 & 1.0 & & & 14 & 1.0 & & & 16 & 1.0 & & \\
\hline AI-included & 702 & 7 & 0.23 & $0.10-0.50$ & 0.0002 & 6 & 0.73 & $0.28-1.93$ & 0.5293 & 8 & 0.79 & $0.34-1.87$ & 0.5952 \\
\hline Tamoxifen only & 4680 & 108 & 0.67 & $0.48-0.93$ & 0.0167 & 50 & 1.17 & $0.65-2.12$ & 0.6042 & 51 & 1.07 & $0.61-1.89$ & 0.8143 \\
\hline \multicolumn{14}{|l|}{$\geq 50$} \\
\hline Nonuser & 1883 & 42 & 1.0 & & & 20 & 1.0 & & & 20 & 1.0 & & \\
\hline AI-included & 1472 & 17 & 0.41 & $0.23-0.72$ & 0.0019 & 6 & 0.30 & $0.12-0.74$ & 0.0092 & 7 & 0.34 & $0.14-0.80$ & 0.0140 \\
\hline Tamoxifen only & 2868 & 69 & 0.95 & $0.64-1.41$ & 0.8034 & 32 & 0.90 & $0.51-1.59$ & 0.7124 & 33 & 0.97 & $0.55-1.73$ & 0.9253 \\
\hline
\end{tabular}

5,687 (75.3\%) had ever used other SERMs and 1,864 $(24.7 \%)$ used AIs only. The majority $(91.1 \%)$ of the AIincluded users used AI sequentially after discontinuing the use of a SERM. In the AI-included users, the median cDDD (interquartile range, IQR) use of AIs, SERMs, and tamoxifen were 468 (196 to 868), 252 (7 to 681 ), and 245 (1 to 672 ) respectively. AIs contributed to $67 \%$ (IQR, 31 to $99 \%$ ) of the total cDDD of antiestrogens use in the AI-included users. The demographic characteristics of the groups are shown in Table 1. The AI-included users 

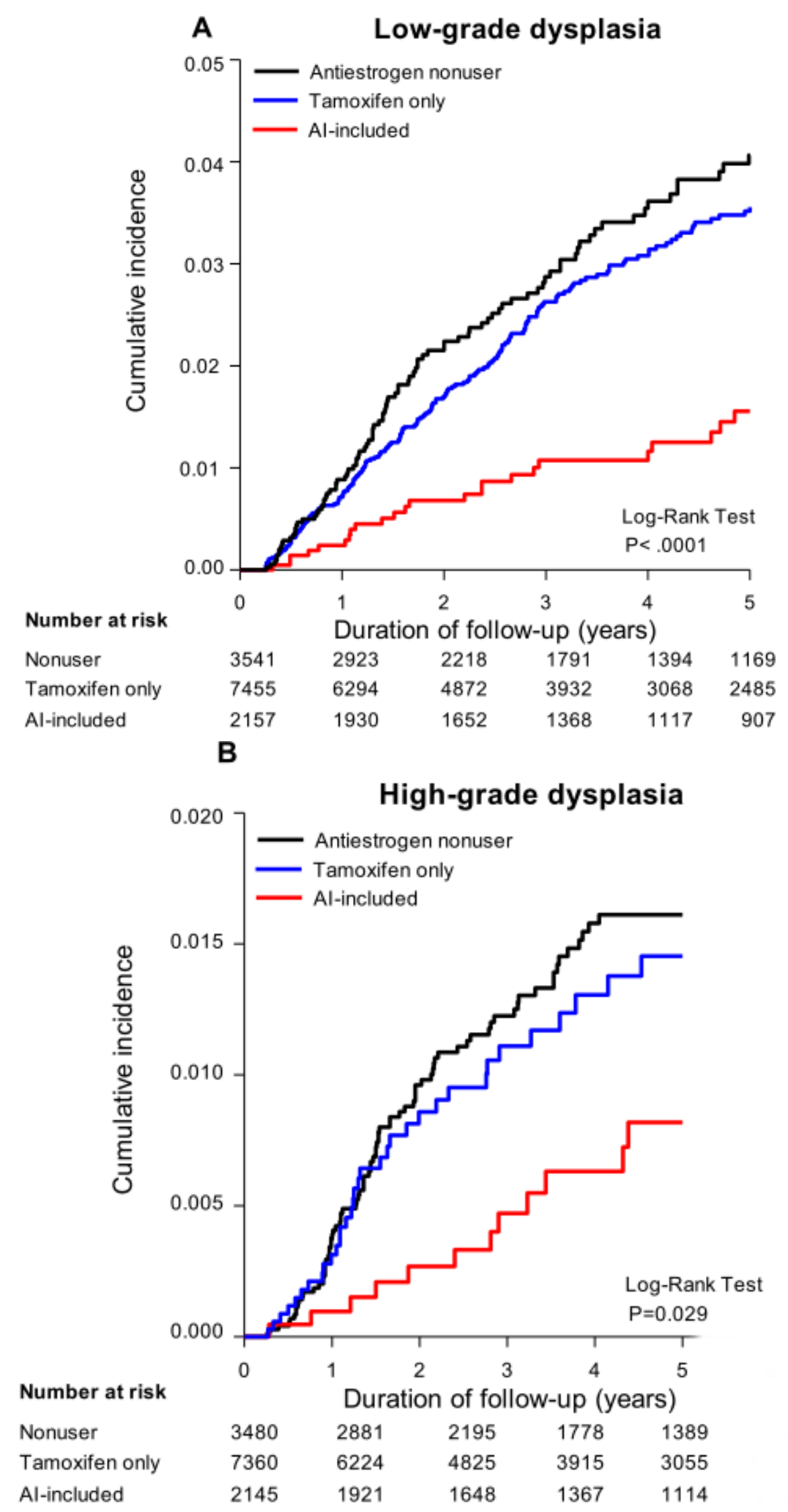

Figure 2: Kaplan-Meier analysis for the association between antiestrogens use and A. low-grade dysplasia, B. high-grade dysplasia, for patients with Pap smear at least once every two year in 5 years follow-up analysis. 
were generally older than the tamoxifen-only users and nonusers. The numbers of subjects identified across the years of the study were similar among the three groups. Greater proportions of nonusers $(70.5 \%)$ and AI-included users $(70.6 \%)$ had received chemotherapy compared to the tamoxifen-only users $(54.1 \%)$. An average of $93.1 \%$ and roughly equal proportions of patients in each group had completed their primary therapy within 270 days after the diagnosis of breast cancer. The AI-included users had a slightly longer follow-up duration (median 4.11 years, IQR 2.29 to 5.00) than the tamoxifen-only users (median 3.75 years, IQR 1.82 to 5.00) and the nonusers (median 3.52 years, IQR 1.65 to 5.00 ). The mortality rate was higher in the nonusers and AI-included users (both 10.7\%) than in the tamoxifen-only users $(2.9 \%)$. A high proportion of antiestrogen users ( $81.4 \%$ in AI-included users and $74.1 \%$ in tamoxifen-only users) adhered to the medication for more than half of the cDDD in study period (days).

After adjusting for age, Pap smear density and chemotherapy (Table 3), the AI-included users exhibited a lower risk of low-grade cervical dysplasia than the nonusers [adjusted hazard ratio $(\mathrm{HR})=0.42,95 \%$ confidential interval (CI), 0.29 to $0.64, P<0.0001]$ in the five-year follow-up analysis. The hazard ratio was more prominent in the patients who had received Pap smears at least once every two years $(\mathrm{HR}=0.32,95 \% \mathrm{CI}, 0.20$ to $0.50, P<0.0001$ ), in the younger (18 to 49 years) group $(\mathrm{HR}=0.23,95 \% \mathrm{CI}, 0.1$ to $0.5, P=0.0002)$, and also in the older $(\geq 50$ years) group ( $\mathrm{HR}=0.41,95 \% \mathrm{CI}, 0.23$ to $0.72, P=0.0019)$.

Similar results were found for high-grade dysplasia in AI-included users in the 10-year follow up $(\mathrm{HR}=0.60$, $95 \% \mathrm{CI}, 0.39$ to $0.93, P=0.0231$ ). A lower risk was also noted in the older $(\geq 50$ years) group ( $\mathrm{HR}=0.44,95 \%$ CI, 0.24 to $0.79, P=0.0058$ ) in subgroup analysis. This phenomenon was also more prominent in the older $(\geq 50$ years) patient who received regular Pap smears at least once every two years in both the 5-year and 10-year follow-up analyses ( $\mathrm{HR}=0.30,95 \% \mathrm{CI}, 0.12$ to $0.74, P=$ 0.0092 and $\mathrm{HR}=0.34,95 \% \mathrm{CI}, 0.14$ to $0.80, P=0.014$, respectively) (Table 3 ). Due to the limited event number, there was no association of antiestrogen use and the incidence of ICC in the 10-year follow-up (Table 2). The use of tamoxifen only revealed a marginal lower risk of cervical neoplasia. A lower risk of low-grade cervical dysplasia was noted in the young age (18 to 49 years) group that had undergone Pap smears at least once every two years $(\mathrm{HR}=0.67,95 \% \mathrm{CI}, 0.48$ to $0.93, P=0.0167)$ (Table 3).

The cumulative incidences of low-and high-grade cervical dysplasia are shown in the Kaplan-Meier analysis in Figure 2A and 2B. The AI-included users exhibited lower cumulative incidences of low- (log-rank test, $P<$ 0.0001 ) and high-grade cervical dysplasia (log-rank test, $P<0.0029)$ compared to the nonuser and tamoxifen-only user groups.

\section{DISCUSSION}

To our knowledge, this is the first population-based study to demonstrate that use of antiestrogen, especially the AI-included antiestrogen use, is associated with a lower incidence of cervical neoplasia. The protection against low grade cervical dysplasia was evident in a manner of no correlation to the age of subjects, whereas for high grade cervical dysplasia it was observed only in subjects $\geq 50$ years old (Table 3 , heterogeneity tests showed no different between subjects at 18-49 and $\geq 50$ years old, $P=0.00541$ and $P=0.0849$ in 5- and 10-years analyses respectively in the main model; $P=0.0969$ and $P=0.2358$ in 5- and 10-years analyses in the regular pap screening subgroup, respectively, data not shown). This is in accordance with the natural histories of cervical tumorigenesis which displays an early onset of low grade dysplasia after HPV infection and a 2 to 5 years period to progress to high grade dysplasia which may last for more than one decade [17]. In accordance with the primary role of Pap screening in the detection of preinvasive cervical lesions, the protective effect was even more obvious in the subjects who had received regular Pap smears. The sensitivity and specificity Pap smear for the detection of high-grade dysplasia or more severe cervical neoplasia in Taiwan is $81.9 \%$ and $98.6 \%$ respectively [18]. Meanwhile, the nation-wide 3-year screening rate increased from $14.5 \%$ in 1995 to $75.9 \%$ in 2014 [19]. In this population with breast cancer, an even higher screening rate was noted. A higher incidence of cervical neoplasias could be expected in these two user groups, but instead, we observed lower incidences. Thus, the hazard ratios for subgroup of "Pap smear at least once every two years" was more closely reflected the protective effects of antiestrogens on the occurrence of cervical neoplasias.

Tamoxifen use exhibited a marginal protection effect on cervical neoplasia, except in the subgroup of young patients with regular Pap smears, a lower risk of low-grade cervical dysplasia was noted (Table 3). This finding might be explained by the fact that tamoxifen acts as an ER agonist rather than antagonist in the uterus $[20,21]$. The long-term use of tamoxifen in breast cancer patients actually increases the risks of endometrial and uterine stromal cancers [22]. However, studies of breast cancer patients who used tamoxifen did not reveal an increase in the incidence of abnormal cervical cytology [23]. Meanwhile, a phase 2 clinical trial reported a modest therapeutic effect of tamoxifen in recurrent non-squamous cell carcinomas of the cervix [13].

Although $78.7 \%$ of the AI-included users had ever used tamoxifen (Figure 1), the cDDD for tamoxifen was only $25.8 \%$ of the total cDDD antiestrogen in this group. Given that tamoxifen was neutral or only modestly effective in reducing the risk of cervical neoplasia, the protective effect of AI-included antiestrogen use can be attributed by the AIs. This result resembles the case of 
antiestrogen use in ER and/or progesterone receptor (PR)positive breast cancer in which AI is more effective than tamoxifen in preventing recurrence of breast cancer [24]. Due to the limited number of cases with pure AI use (only 1,864 or $6.7 \%$ of all of the antiestrogens users), this study was not able to provide direct evidence regarding pure AI in the protection against cervical neoplasia.

This study has several strengths. First, this naturally occurring and passively followed cohort was devoid of selection or recall bias. Second, the use of antiestrogens in breast cancer patients was based on the expression of the ER and/or PR in the tumors, which is unrelated to the systemic health or the occurrence of cervical neoplasia. Third, because antiestrogens are essential for preventing the recurrence of breast cancer, drug adherence of the antiestrogen users was extraordinarily strong; $81.4 \%$ of AI-included users, and $74.1 \%$ of tamoxifen-only users exhibited adherences above half of the cDDD in the study period. Fourth, the main tool for outcome detections, the Pap smear, is sufficiently sensitive and specific and was widely applied in the study population. Finally, the 10year follow-up period was sufficient to identify most of the occurrences of non-invasive cervical neoplasias. Due to the transient nature of low-grade cervical dysplasias and the fact that tamoxifen is typically used for five years after the primary therapy for breast cancer, we purposely set the analysis period to 5 years for low-grade dysplasia. In the analysis of high-grade cervical dysplasia, of which in situ carcinomas comprise a major portion, and the natural history is as long as 10 years or more, a longer follow-up is mandatory. Indeed, in the 10-year follow up, the AIincluded users of postmenopausal ages exhibited a low risk $(\mathrm{HR}=0.34,95 \% \mathrm{CI}, 0.14$ to $0.80, P=0.014)$ for high-grade cervical dysplasias. Additionally, the lack of ICC in the study population may due to relatively adequate screening that prevent the development of cancer.

There are also limitations of this study. As mentioned previously, the effect of AI was analyzed in the larger group of AI-included users and not in a group of pure AI users. Information regarding other confounders of cervical cancer, such as HPV infection status [2] [3], smoking [25], number of sexual partner [26] and sex hormone exposure (e.g. menopause, parity, and oral contraceptives pill use) was lacking. The smoking rate among Taiwanese women is as low as 4.3\% [27]. Oral contraceptive use is also not popular in Taiwan. Therefore, the effect from these two factors may be minimal. Regarding to the major confounder of HPV infection, discrepant risks or prevalence of HPV infection may not present between groups, although the tamoxifen-only users, who exhibited a lower mortality rate, may have been more likely to maintain sexual activity and more prone to HPV infection.

In summary, this study demonstrated that antiestrogen use especially AI is associated with a reduction in cervical dysplasia.

\section{MATERIALS AND METHODS}

\section{Study population and study design}

The Taiwan National Health Insurance (NHI) database consists of health information from 23 million inhabitants since 1997. The database includes comprehensive disease diagnoses, hospital admissions, outpatient visits and prescription medications. Data for this study were obtained from the Registry for Catastrophic Illness Patient Database (RCIPD), which is a subset of the Taiwan NHI database that contains the complete medical records of all cancer patients. Due to the Registry of Catastrophic Illness, cancer patients receive medical care nearly free of charge while under NHI coverage. This database has been used extensively for epidemiologic research, and the information about diagnoses, prescription medications and hospitalizations is of reliable quality [28].

In this study, newly diagnosed breast cancer patients who were registered with the RCIPD from January 1, 2002 to December 31, 2012 were identified using the International Classification of Diseases, 9th Revision (ICD-9), codes 174.0 to174.9. Figure 1 shows the study design, exclusion criteria and the status of antiestrogen use in the study population. We excluded subjects who were male or younger than 18 years old, those with histories of cervical dysplasia, cervical carcinoma in situ (CIS), ICC and other cancers, those who had undergone hysterectomy, bilateral oophorectomy, cervical amputation, or cervical conization before or on the date of breast cancer diagnosis. We also excluded those with lymph node or distant metastases and subjects who did not receive standard primary therapy (an operation and /or chemotherapy) for breast cancer. To standardize the follow up protocol of the antiestrogen users and nonusers, those who had used antiestrogen before the end of standard primary therapy or one year after the diagnosis of breast cancer were excluded. The defined daily dose (DDD) advocated by the WHO was used to standardize the comparisons of drug usage between the different drugs, and the cumulative DDD (cDDD) of the antiestrogen users was calculated. Those with antiestrogen use that was less than $90 \mathrm{cDDD}$ and whose follow-up periods were less than three months were also excluded.

The antiestrogens covered by the NHI during the study period for breast cancer adjuvant therapy included four SERMs (tamoxifen, raloxifen, toremifene and clomifene) and four AIs (anastrozole, letrozole, aminoglutethimide, and exemestane). To demonstrate the compliance with and consistency of the antiestrogen use, adherence was calculated by dividing the cDDD by duration of the follow-up period (days). To compare the effect of the different antiestrogens on cervical neoplasia, 
the patients were divided into three groups: nonusers, antiestrogen users who had ever used aromatase inhibitors, and antiestrogen users who had used tamoxifen only.

The follow-up scheme is shown in supplement (Figure S1). All breast cancer patients with or without antiestrogen use were followed after completion of the standard primary therapy for breast cancer. The follow up was initiated when the antiestrogen users began to use antiestrogen and when the nonusers had received the last primary therapy. All patients were followed until the occurrence of the most severe form of cervical neoplasias, the end of the study or death. Thus, if patient's medical records contained high-grade dysplasia and ICC during follow up period, only ICC was counted. The identification of ICC was based on a new registration of ICC in the RCIPD or by the diagnosis of ICC during hospitalization using the ICD-9 codes 180.0 to 180.9 . High-grade cervical dysplasia was identified by the diagnostic codes for cervical CIS (ICD-9 code 233.1) and cervical dysplasia (ICD-9 code 622.1) accompanied by the therapeutic procedure of cervical conization. Low-grade cervical dysplasia of the cervix was identified using the ICD-9 code 622.1 accompanied by procedures for cervical biopsy and/or endocervical curettage.

We explored several risk factors including age [6], Pap smear density [29], and chemotherapy treatment [30] that might have interfered with the association between antiestrogen use and the risk of cervical neoplasia. Pap smear density was calculated as the number of Pap smears divided by the number of follow-up person-years. This study was approved by the Research Ethics Committee of the medical center Hualien Tzu Chi Hospital, Hualien, Taiwan (IRB101-98).

\section{Statistical analysis}

Based on a Cox proportional hazards model, the hazard ratios (HRs) and accompanying 95\% confidence intervals (CIs) were computed with adjusting for age at the time of breast cancer diagnosis, Pap smear density and chemotherapy. Since death is a competing risk for loss to follow-up, we also did a competing risk analysis by Fine and Gray method [31]. The consistencies and differences in the risk of cervical neoplasia were evaluated by conducting subgroup analyses based on age and Pap smear. To test whether excluding subjects whose follow-up periods were less than three months would cause selection bias, sensitivity analyses of including all the subjects or excluding the subjects with different follow-up period were conducted (Table S1).The cumulative incidence of cervical neoplasia was plotted using the Kaplan-Meier method, and the differences between the curves were tested with the log-rank test. The occurrence of cervical dysplasia is always identified by Pap screening [18], therefore, the cumulative incidence of cervical dysplasia was analyzed in the subgroup of patients who underwent
Pap smears at least once every two years. The statistical analyses were performed using SAS, version 9.4 (SAS Institute, Inc., Cary, NC) and all tests were two-sided.

\section{Abbreviations}

$\mathrm{AI}$ : aromatase inhibitor; $\mathrm{HR}$ : hazard ratio; $\mathrm{CI}$ : confidence interval; HPV: human papilloma virus; ICC: invasive cervical cancer; ER: estrogen receptor; SERM: selective estrogen receptor modulator; NHI: National Health Insurance; RCIPD: Registry for Catastrophic Illness Patient Database; CIS: cervical carcinoma in situ; DDD: defined daily dose

\section{ACKNOWLEDGMENTS AND FUNDING}

The authors are grateful to Dr. Tsung-Cheng Hsieh for advices in statistics. The study was supported by National Science Council, Taiwan and Buddhist Tzu Chi General Hospital, Taiwan, Contract No. NSC 102-2629-B303-001 and TCRD101-98.

\section{CONFLICTS OF INTEREST}

The authors declare that they do not have any conflicts of interest.

\section{REFERENCES}

1. Sankaranarayanan R, Ferlay J. Worldwide burden of gynaecological cancer: the size of the problem. Best Pract Res Clin Obstet Gynaecol. 2006;20:207-25.

2. Walboomers JM, Jacobs MV, Manos MM, Bosch FX, Kummer JA, Shah KV, Snijders PJ, Peto J, Meijer CJ, Munoz N. Human papillomavirus is a necessary cause of invasive cervical cancer worldwide. J Pathol. 1999;189:129.

3. Schiffman M, Castle PE, Jeronimo J, Rodriguez AC, Wacholder S. Human papillomavirus and cervical cancer. Lancet. 2007;370:890-907.

4. International Collaboration of Epidemiological Studies of Cervical Cancer. Cervical carcinoma and reproductive factors: collaborative reanalysis of individual data on 16,563 women with cervical carcinoma and 33,542 women without cervical carcinoma from 25 epidemiological studies. Int J Cancer. 2006;119:1108-24.

5. Appleby P, Beral V, Berrington de Gonzalez A, Colin D, Franceschi S, Goodhill A, Green J, Peto J, Plummer M, Sweetland S. Cervical cancer and hormonal contraceptives: collaborative reanalysis of individual data for 16,573 women with cervical cancer and 35,509 women without cervical cancer from 24 epidemiological studies. Lancet. 2007;370:1609-21.

6. Plummer M, Peto J, Franceschi S. Time since first sexual 
intercourse and the risk of cervical cancer. Int $\mathrm{J}$ Cancer. 2012;130:2638-44.

7. Chung SH, Wiedmeyer K, Shai A, Korach KS, Lambert $\mathrm{PF}$. Requirement for estrogen receptor alpha in a mouse model for human papillomavirus-associated cervical cancer. Cancer Res. 2008;68:9928-34.

8. Brake T, Lambert PF. Estrogen contributes to the onset, persistence, and malignant progression of cervical cancer in a human papillomavirus-transgenic mouse model. Proc Natl Acad Sci U S A. 2005;102:2490-5.

9. Chung SH, Franceschi S, Lambert PF. Estrogen and ERalpha: culprits in cervical cancer? Trends Endocrinol Metab. 2010;21:504-11.

10. Chung SH, Lambert PF. Prevention and treatment of cervical cancer in mice using estrogen receptor antagonists. Proc Natl Acad Sci U S A. 2009;106:19467-72.

11. Castle PE. Do selective estrogen receptor modulators treat cervical precancer and cancer? Time to pool data from relevant trials. Int J Cancer. 2011;128:997-8.

12. Munger K. Are selective estrogen receptor modulators (SERMs) a therapeutic option for HPV-associated cervical lesions and cancers? Am J Pathol. 2014;184:358-61.

13. Bigler LR, Tate Thigpen J, Blessing JA, Fiorica J, Monk BJ. Evaluation of tamoxifen in persistent or recurrent nonsquamous cell carcinoma of the cervix: a Gynecologic Oncology Group study. Int J Gynecol Cancer. 2004;14:8714.

14. Olin JL, St Pierre M. Aromatase inhibitors in breast cancer prevention. Ann Pharmacother. 2014;48:1605-10.

15. Cuzick J, Sestak I, Cawthorn S, Hamed H, Holli K, Howell A, Forbes JF. Tamoxifen for prevention of breast cancer: extended long-term follow-up of the IBIS-I breast cancer prevention trial. Lancet Oncol. 2015;16:67-75.

16. Visvanathan K, Hurley $\mathrm{P}$, Bantug E, Brown $\mathrm{P}$, Col NF, Cuzick J, Davidson NE, Decensi A, Fabian C, Garber J, Katapodi M, Kramer B, Morrow M, et al. Use of pharmacologic interventions for breast cancer risk reduction: American Society of Clinical Oncology clinical practice guideline. J Clin Oncol. 2013;31:2942-62.

17. Ostor AG. Natural history of cervical intraepithelial neoplasia: a critical review. Int J Gynecol Pathol. 1993;12:186-92.

18. Chao A, Hsu KH, Lai CH, Huang HJ, Hsueh S, Lin SR, Jung SM, Chao FY, Huang SL, Huang CC, Yang JE, Chang TC. Cervical cancer screening program integrating Pap smear and HPV DNA testing: a population-based study. Int J Cancer. 2008;122:2835-41.

19. Taiwan Public Health Report. 2013, pg 97, table 5-9. http://www.hpa.gov.tw/BHPNet/Portal/file/ FormCenterFile/201410240949220444/online_english/ index.html\#97/z. Accessed November 12, 2015.
20. Friedrich M, Mink D, Villena-Heinsen C, Woll-Hermann A, Schmidt W. Tamoxifen and proliferation of vaginal and cervical epithelium in postmenopausal women with breast cancer. Eur J Obstet Gynecol Reprod Biol. 1998;80:221-5.

21. Persson I, Yuen J, Bergkvist L, Schairer C. Cancer incidence and mortality in women receiving estrogen and estrogen-progestin replacement therapy-long-term followup of a Swedish cohort. Int J Cancer. 1996;67:327-32.

22. Daniel Y, Inbar M, Bar-Am A, Peyser MR, Lessing JB. The effects of tamoxifen treatment on the endometrium. Fertil Steril. 1996;65:1083-9.

23. Gill BL, Simpson JF, Somlo G, McGonigle KF, Wilczynski SP. Effects of tamoxifen on the cytology of the uterine cervix in breast cancer patients. Diagn Cytopathol. 1998;19:417-22.

24. Dowsett M, Cuzick J, Ingle J, Coates A, Forbes J, Bliss J, Buyse M, Buzdar A, Colleoni M, Coombes C, Snowdon C, Gnant M, Jakesz R, et al. Meta-analysis of breast cancer outcomes in adjuvant trials of aromatase inhibitors versus tamoxifen. J Clin Oncol. 2010;28:509-18.

25. Jiang J, Pang H, Liu B, Nasca PC, Zhang B, Wu Y, Han W, Gates M, Lu T, Zou X, Xue F, Hou L, Wang Z, et al. Effects of active, passive, and combined smoking on cervical cancer mortality: a nationwide proportional mortality study in Chinese urban women. Cancer Causes Control. 2015;26:983-91.

26. Liu ZC, Liu WD, Liu YH, Ye XH, Chen SD. Multiple Sexual Partners as a Potential Independent Risk Factor for Cervical Cancer: a Meta-analysis of Epidemiological Studies. Asian Pac J Cancer Prev. 2015;16:3893-900.

27. Health Promotion Administration, Ministry of Health and Welfare, Taiwan: Bureau of Health Promotion Department of Health, Aldult Smoking Behavior Surveillance System (ASBS). http://www.hpa.gov.tw/BHPNet/English/ ClassShow.aspx?No $=201502020004$. Accessed November 12, 2015.

28. Wu CY, Chen YJ, Ho HJ, Hsu YC, Kuo KN, Wu MS, Lin JT. Association between nucleoside analogues and risk of hepatitis $\mathrm{B}$ virus-related hepatocellular carcinoma recurrence following liver resection. JAMA. 2012;308:1906-14.

29. Peirson L, Fitzpatrick-Lewis D, Ciliska D, Warren R. Screening for cervical cancer: a systematic review and meta-analysis. Syst Rev. 2013;2:35.

30. Lorusso D, Petrelli F, Coinu A, Raspagliesi F, Barni S. A systematic review comparing cisplatin and carboplatin plus paclitaxel-based chemotherapy for recurrent or metastatic cervical cancer. Gynecol Oncol. 2014;133:117-23.

31. Zhang $\mathrm{X}$, Zhang MJ, Fine J. A proportional hazards regression model for the subdistribution with rightcensored and left-truncated competing risks data. Stat Med. 2011;30:1933-51. 